\title{
El ritmo de la historia y la región*
}

\author{
José Lametras \\ El COlEgio de MichoAcán
}

$\mathbf{P}$

ermitaseme la recurrencia a la composición y a la estructura musical para, metafóricamente, referir una primera idea global de la cuestión general. Me parece que, como la historia, también las regiones tienen un ritmo, una alternancia periódica de los elementos de un proceso, un orden en el que se articulan hechos en el tiempo, mediante la sucesión periódica de acontecimientos, situaciones y coyunturas. En términos de ritmo biológico, por otro lado, también se puede pensar en la región como un espacio en el que se presentan modificaciones periódicas y cícli-

* Una primera versión de este trabajo se presentó en la reunión "Historia regional: Retos y posibilidades" organizada por el CIEsAsSureste y el Instituto Chiapaneco de Cultura. San Cristóbal de las Casas, 9-11 de diciembre de 1992. cas en una comunidad "biótica", que afectan a la actividad y distribución de los individuos pero no al número total. Por lo general, los ritmos obedecen, igualmente en un sentido vital, a cambios del medio ambiente que suponen un lapso temporal.

Siguiendo el lenguaje metafórico, lo regional y lo histórico pueden ser observados en los confines de la armonía, en el sentido de la lógica que exhiben la simultaneidad de los hechos atendiendo a los acordes (léase características y modos de integración intrarregional) de sus intervalos y a su relación con "notas extrañas" a tales acordes (léase hechos ajenos, extrarregionales), los cuales, sin pertenecer a los modos de integración regional, sustituyen a algunos de los originados en su ámbito.

Tampoco parece inadecuada la ima- 
gen de la melodía, en cuanto la región puede concebirse, constitutivamente, como una sucesión de hechos (notas en términos musicales) que componen un periodo completo y constituyen el elemento vertical -temporaldel espacio regional. Dentro de esta última figura, y abusando de la metáfora musical, puede decirse que, en la composición regional, uno puede hablar de "monofonía", "polifonía" y "homofonía" (apoyo de la constitución armónica regional en otras armonías). En cuanto a los "tempos" regionales puede uno pensar en los "andantes", "maestosos", "cantabiles" $y$ "allegros", ello también es adecuado, convencionalmente, para asociar a un espacio territorial, un compás temporal de integración o disolución, el ritmo con el que discurre, a manera de una obra teatral, la vida de una colectividad en un espacio y en una temporalidad acotada internamente y condicionada externamente. La idea del "primo tempo" también es sugerente para apreciar el proceso de formación regional que, tras cambios perturbadores, retoma su dirección original asimilando o refuncionalizando en su favor las alteraciones que le llegan del exterior.

Lo hasta aquí dicho es simplemente una apreciación o una representación personal de lo que diversos estudiosos de la regionalización y lo regional han postulado como la esencia de esa problemática. Tales observadores se han valido, en su caso, de referentes múltiples y de la combinación entre ellos para tratar de delimitar -por lo común sin dejar de tomar en cuenta la dimensión temporal- el espacio te- rreno relativo de una región. Vale la pena por ello dar cuenta, aunque sea brevemente, de algunos criterios sobresalientes que historiadores y otros científicos sociales han utilizado para representarse reflexivamente la región y su dimensión histórica. Antes de ello, considero necesario apelar a ciertas disimilitudes que representa la región y lo regional en las culturas de los investigadores de tal fenómeno.

Quizá, para la mayoría de los investigadores preocupados por la región, el punto de partida lo constituye un simple concepto que les permita la descripción de hechos bidimensionales (espacio y tiempo), su clasificación en términos de orden o nivel y la relación que entre diversos niveles se establezca. Mas, como sabemos, los conceptos, además de posibilitar la descripción y la clasificación, conducen hacia la previsión de objetos cognoscibles.

Aquí cabe observar que la sola descripción y clasificación de los hechos presentes y pretéritos en busca de su lógica, no basta, al menos para disciplinas como la antropología, la economía y la sociología, para la demarcación regional y la explicación de su conformación y variación en el tiempo. Es necesario "un planteamiento previo de problemas a partir de teorías y conceptos transregionales", ${ }^{1}$ basado en la consideración de la región como

un concepto histórico, politético, cuyo significado se modifica por circunstancias de tiempo y de lugar $[. .$.$] (regiones)$ en fin $[\ldots]$ un recurso metodológico $[\ldots]$

' De la Peña,"Estudios", 1981. 
que puede ser exigido, incluso, por la propia teoría. ${ }^{2}$

Varias disciplinas se han preocupado por definir espacios regionales $y$ se han ocupado de diversos fenómenos que se presentan al interior de ese espacio. A la mayoría, si no a la totalidad de ellas, les es de gran utilidad el tratamiento historiográfico, mas no todas se interesan por el todo, la globalidad de los acontecimientos que se presentan en la región, y eso se comprende por la parcelización que ha de hacerse de acuerdo con los lineamientos disciplinarios.

Por otro lado, en la biología el concepto región se asocia estrechamente a los de nicho ecológico y ecosistema. Su interés son los procesos y los acoplamientos por los cuales agregados más o menos heterogéneos de seres vivos coexisten y se adaptan a un territorio y sus recursos naturales.

Pero la geografía contemporánea ha ido más allá del concepto de "región natural" $e$ insistiendo en la importancia de la historia se ocupa de la formación histórica de los territorios, a la que condicionan, relativamente, factores fisiográficos. Reconocen estos geógrafos, como los antropólogos, historiadores y otros científicos, que los espacios no sólo son ocupados sino también percibidos, interpretados $y$ realizados históricamente por sus habitantes, en los términos de cumplir en ellos lo que las apariencias daban lugar a esperar. Tales realizaciones constituyen una cadena que va desde la práctica hacia la experiencia y

${ }^{2}$ lbid. el conocimicnto. El habitar, usar y experimentar un espacio lleva a un conocimiento acumulado y a una planificación cotidiana que origina tanto continuidades como cambios. La percepción del espacio comienza en los lugares vividos en la vida diaria y familiar, continúa en los espacios sociales que son significativos para los habitantes de las localidades, y llega, igualmente a través de representaciones, a una conciencia, tanto práctica como "reflexiva" de lo regional. Todos estos niveles de percepción del espacio, que poseen su propia lógica y especificidad manifiestan una forma de cstructuración regional.

Los economistas tienen, a su vez, sus propias formas de matar pulgas, de abordar el problema regional. Son, quizá junto con los practicantes de otras disciplinas, los que han sido más sugerentes para los antropólogos e historiadores metidos en el problema de la regionalización. Los economis. tas comienzan propiamente tratando de dividir un espacio territorial en términos, recursos y población, observan las comunicaciones y los centros de producción, distribución y articulación de mercados. Les interesa localizar agentes y actividades económicas a todo nivel; luego quitan la cuadricula para descubrir redes, las redes que permiten apreciar las constituciones verdaderamente amibáceas de las regiones. Utilizan la historia para apreciar el movimiento, la dinámica, de sus regiones. Atienden a lo que dicen otros, como los biólogos, los geógrafos y los historiadores, y particularmente a los que en ese espacio se preocupan por "trazar series de aconteci- 
mientos pasados en términos de relación de causa y efecto" 3 o de estudiar, como algunos historiadores, la evolución de las manifestaciones de là vida social preguntándose, la mayoría de las veces, el porqué pero no el cómo. Los economistas abocados a la regionalización son quizá los más ávidos buscadores de una teorización del problema y el seguimiento de tal actitud ha preocupado sensiblemente a muchos antropólogos sociales, a historiadores, demógrafos y sociólogos.

Conviene a estas alturas convenir en un listado de asuntos importantes $y$ pertinentes para quienes se preocupan y ocupan de la problemática regional, que comienza en un momento con planteamientos conceptuales y metodológicos y concluye en otro con explicaciones estructuralistas, funcionalistas, historicistas, evolucionistas o culturológicas de índole teórica.

Lo que en primer lugar aparece como evidente es el hecho de que cada disciplina que se aboca al estudio de una región requiere, de hecho, de la recurrencia original y final de los resultados que de la exploración de lo regional se derivan de otros enfoques. En esta forma los mirares de los biólogos, geógrafos, demógrafos, ecólogos, economistas, sociólogos, historiadores y psicólogos tienen un particular significado, en cuanto que arriman materiales idóneos para una antropología regional, los cuales constituyen una manera de profundizar y ampliar -aunque sea en plan de utilitaristas, pepenadores o intérpretes- un enfo- que determinado que se obstaculizaría desde un principio al proponerse una meta holística como principio de descripción y de explicación.

Por esta razón, consciente de sus limitaciones y dirigida a sus finalidades, la antropología regional -que igual puede ser nominada como antropología histórica, del desarrollo cultural y demás-abreva y ha abrevado en los resultados que proceden de investigaciones de naturaleza arqueológica, etnológica, sociológica, historiográfica, ecológica, económica y legal. Una derivación de esa actitud parece haber sido redituable cuando uno analiza creaciones y adaptaciones de los métodos antropológicos al problema regional. Una más, quizá la más importante, es la orientación que la antropología regional ha tenido de esa especie de simbiosis en relación con otras ciencias.

A la historia regional apelan, tanto los que se interesan por los proce. sos de formación económico social, como los que investigan y tratan de establecer el origen de un orden, una jerarquía, en la que hay una pluralidad, y en este sentido se trata de una pluralidad de órdenes en una sola jerarquía y el orden es simplemente el grado, el plano o el nivel de un orden total. Justamente el estudio de la formación de la nación y el cle la formación del Estado, en relación a las formaciones regionales pretende encontrar los órdenes que históricamente han relacionado a uno con otro. De ahí que sea importante referirnos brevemente a asuntos

${ }^{3}$ Lewis, Historia, 1972, p. 11. 
... DE HISTORIA, HISTORIAS E HISTORIETAS...

... que son de provecho para la historiografía regional, comenzando por un nivel general y macro, y aceptando que

la historia se ocupa de estudiar las relaciones que los hombres han establecido en las sociedades del pasado, la interacción entre dichas relaciones y los modos culturales que generan, $y$ los acontecimientos con que se expresa el conjunto. 4

Para la historia de visión global, a la que se someten tanto el enfoque como la selección de datos y las conclusiones, como para las historias que parcelan la realidad, otras disciplinas se convierten en inspiradoras $y$ auxiliares. Esto es así, tanto cuando el historiador toma los datos directamente de la geografía, economía, politología, antropología, sociología y demás, como cuando dentro de la propia ciencia de la historia

se ha llegado a afinar tanto los instrumentos de análisis [...], que ya la mirada de un solo historiador parece no ser suficiente para abordar el conjunto de actividades humanas que constituyen la historia [parn quienes] es menester dividir el acontecer, no sólo err épocas, sino en aspectos [económicos, sociales, políticos, artísticos, científicos, culturales, ideológicos, ctcétera]. ${ }^{5}$

Se advierte igualmente que "cada

\footnotetext{
${ }^{4}$ Diccionario Enciclopédico Grijalbo, "Historia".

5 Matute, Teoría, 1981, p. 25.
}

vez se plantea con más frecuencia la imposibilidad de capturar las interrelaciones de los aspectos en que se divide la cultura". 6

Esta situación rompe con el ideal hegeliano que considera a la historia como una ciencia global de una realidad global y lleva a pensar los riesgos de la especialización, el empirismo, el monografismo y la parcelación del conocimiento. Tal problema lo señala Edmundo O'Gorman, en términos reflexivos respecto al uso del saber para ventaja del hombre, ${ }^{7}$ advirtiendo que

el cscollo fundamental de toda filosofía de la historia es la dificultad de conceptuar la pluralidad de los hechos dentro de una unidad significativa: aprehender la multiplicidad como un todo.

El afán o la pretensión de holismo había sido una tradición generalizada entre los antropólogos hasta que la disciplina ingresó al estudio de sociedades complejas. No obstante, ellos han buscado unidades espaciales -como la región-para tratar de permane. cer ficles a su afecto por la globalidad y a su objetivo de generalizar y "descubrir" leyes. Todo esto los contrasta con la mayoría de los historiadores.

La teorización constituye una diferencia relativa. I. M. Lewis ${ }^{8}$ escribe

Ia historia sigue siendo esencialmente una manera de considerar los datos y de preguntar y responder a la pregunta

${ }^{6}$ Ibid.

7 O'Gorman, "Ilistoria", 1974 (publicado originalmente en 1956).

${ }^{8}$ Lewis, Historia, 1972. 
"epor qué?" con relación a acontecimientos pasados en términos de causa y efecto -y continúa-: la antropología social es, asimismo, primera y principalmente, una manera de reunir $y$ analizar la misma clase de datos, aun cuando su empleo geográfico y cronológico tradicionalmente ha diferido de modo considerable del que hasta fecha reciente atraía la atención de los historiadores más ortodoxos. 9

Luego observa, al referirse a los trabajos monográficos -frecuentemente particularistas como los de los historiadores- de tendencia generalizadora y comparativa - no del todo ausente en los historiadores ortodoxos--, que en los antropólogos

la teoría se ve con más claridad $[\ldots]$ se relaciona $[\ldots]$ con las propiedades distintivas de complejos institucionales [...] pero va más allá y alcanza lo que en la valoración más baja puede caracterizarse como "perspicacias" con respecto a la naturaleza y consecuencias del conflicto y la competencia, las relaciones entre los poderes secular y místico, las implicaciones de los diferentes tipos de actividad, de marginalidad o las concomitancias sociales de la división de sexos. ${ }^{10}$

Otra cuestión que atañe a la historiografía y a la antropología tiene que ver con el particularismo, procreador de historias y etnografias singulares, condicionador de la relación y de la generalización que coadyuva a la teorización. Desde esta perspectiva es posible abordar la cuestión de la región

9 Ibid., p. 11.

${ }^{10}$ Ibid., pp. 9-12. Cursivas !. L. pero sin que ello trascienda en la formulación de mecanismos generalizados, en las formas de agración y desintegración regional respecto a factores de carácter más amplio.

No obstante que las historias macrorregionales son de importancia para la comprensión general de la región -demuestran la relativa importancia que los hechos históricos extrarregionales tienen para las historias y las formaciones sociopolíticas de dimensión regional-, no nos ocuparemos de ellas en cuanto a sus implicaciones o condicionamientos para construir la historia nacional y del Estado. Adelante explicitaremos algo sobre el asunto, pero en el sentido inverso: ¿qué tanto las historias regionales y su relación inciden en la construcción de historias más generales, salvando las dificultades de las "totalidades" y las "globalidades" ya referidas?

Las historias regionales, por cierto, también pueden enriquecerse con historietas, con narraciones cortas, con los anecdotarios que se recogen de los informantes "en vivo" o de la documentación escrita, que no son nada despreciables cuando uno los reúne, los selecciona como "parches compatibles" mediante la crítica, para la elabo. ración de un tejido en el que desaparecen las incongruencias y los mitos para desembocar en la significación que en los individuos han tenido los hechos sociales.

\section{MAGNITUD DE ACONTECERES $Y$ VOLUNTAD HISTORIOGRÁFICA}

Para aquellos historiadores que, sin negar el ideal que constituye la historia global, advierten la complejidad y plu- 
ralidad de los hechos que constituyen la actividad humana, la historia rural francesa ${ }^{11}$ constituye, sin lugar a du. das, un excelente modelo de referencia para interrelacionar una historia nacional con las de su provincia. Precisamente, como consigna De la Peña ${ }^{12}$ al traer a cuenta cómo es tratada la región en la historia social contemporánea, historiadores como Lucien Febvre y Marc Bloch, luego de abandonar la historiografia superestructural y anecdótica, plantearon "la necesidad de una 'geografía histórica'", de la búsqueda del arraigo espacial de los acontecimientos, del conocimiento "de los fundamentos naturales ofrecidos a las fuerzas productivas desarrolladas por el hombre en cada una de las etapas atravesadas por la economía" ${ }^{13}$ La revisión continúa con el énfasis que los seguidores de la llamada historiografía coyuntural ponen

en las variaciones a largo plazo, detectables en series estadísticas continuas, que no pueden explicarse por constantes geográficas o estructuras intemporales, sino que exigen modelos interpretativos más complejos. ${ }^{14}$

Es aquí donde los historiadores de lo local y de la formación, de la nación y el Estado, que se ocupan de la historia regional, tratan de dar respuesta a la relación histórica entre realidades históricas de distinta magnitud: la colonización, el campesinado, el mercado, la industrialización, la urbani-

11 Bloch, Frencb, 1973.

12 De la Peña, "Estudios", 1981.

13 Vilar, "Fundamentos", p. 13.

14 De la Peña, "Estudios", 1981, p. 48. zación y la regionalización, las clases sociales y otros.

Para los historiadores de lo local, observa De la Peña,

la región es un marco de referencia que surge irremediablemente al hablar de fenómenos locales -pero que varía a través del tiempo-, cuyos componentes "estratigráficos" son las oleadas de poblamiento, los sistemas de propiedad territorial y su concreción en patrimonios y heredades, los sistemas de producción agraria y de organización del trabajo, la movilidad de la mano de obra, las formas de dominación administrativa e ideológica y sus dimensiones espaciales, las configuraciones simbólicas (lengua, arte ritual), la conciencia de un espacio propio [lo cual es propiamente historia. Cursivas J.L. . ${ }^{15}$

Los historiadores de la nación y del Estado, por su lado

cucstionan radicalmente la correspondencia entre Estado y nación: niegan que el hecho nacional pueda subordinarse a factores de continuidad política. La nación es la historia de un tejido inextricable de etnia, política y economía, y la región -en la acepción de los historiadores nacionales- es la expresión espacial de tal tejido. ${ }^{16}$

Me parece que cada una de estas posiciones es válida, interesante y productiva y que, antes que oponerse, pueden ser complementarias a la luz de los hechos históricos globales que,

15 Ibid.

16 Ibid., pp. 28-29. 


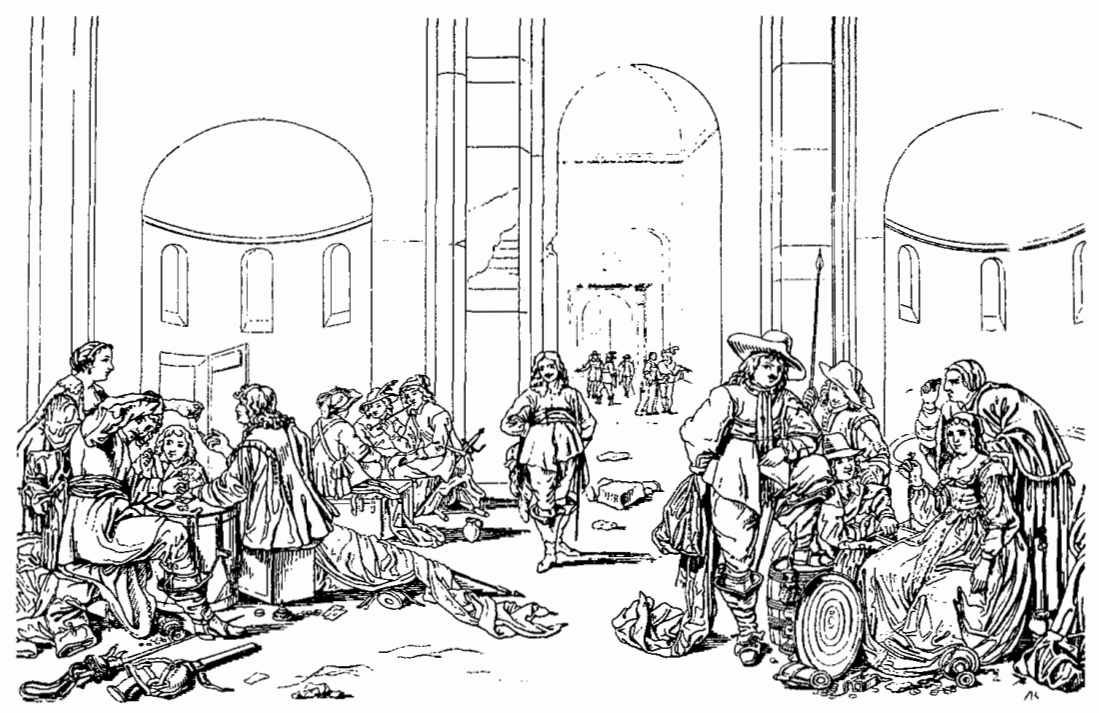

a partir de la conquista y la colonización hispana de lo que hoy es la república mexicana, han sido significativos para delimitar, histórica y territorialmente, la diversidad de regiones en la nación.

\section{PRECONDICIONES Y CONDICIONES}

INICIALES DE LA FORMACIÓN DEL ESPACIO SOCIAL NOVOHISPANO

La organización prehispánica del espacio en función de la producción, los asentamientos poblacionales, la guarda del territorio, la densidad demográfica y la división y jerarquía gubernamental antigua, constituyeron las precondiciones fundamentales para la progresiva formación regional en Nueva España.

El tipo genérico de las instituciones políticas indígenas, caracterizado por José Miranda como "tribal-territorial en la base, clasista-funcional en la estructura, y señorial feudal en cl vínculo o lazo político", ${ }^{17}$ tomanclo en cuenta las variaciones en la organización política, entre las cuales

la más extendida parece haber sido la del Estado mexica y sus federados Texcoco y Tacuba, consistente en un jefe supremo -asistido por algunos altos funcionarios-, una asamblea electoral, un consejo, varios jefes locales (caci-

17 Miranda, Instituciones, 1952, p. 7. 
ques) y numerosos señores subordinados a éstos (principales), ${ }^{18}$

fue aprovechada parcial pero provechosamente por los conquistadores.

La institución del tributo y sus implicaciones para la distribución y concentración de bienes y la constitución de redes comerciales y centros de mercado, fueron igualmente útiles para determinar la distribución de encomiendas a lo largo y lo ancho del territorio ocupado; las encomiendas, sus sedes territoriales como ejes de pueblos y barrios, ayudaron a establecer una de las redes articuladoras de los incipientes centros urbanos, a través de las cuales se transmitía el poder im. perial.

Sabemos todo lo que la propia guerra de conquista, la desintegración de la producción económica, social y política causada por las epidemias, los abusos de los empresarios, colonos y autoridades afectaron a esas precondiciones de la formación original del espacio social novohispano y a la integración temprana de sus regiones. Integración en la que la sarta de misio. nes religiosas contribuyó, como las encomiendas, a establecer redes de articulación con la metrópoli y sus delegados en América cumpliendo funciones de introducción, ocupación y enlace político -bicéfalamente como el águila de los austrias- por el lado de la Iglesia y por el correspondiente al Estado civil. Los religiosos, mancornados por disposiciones reales con los encomenderos, constituyen otro tipo de conexión, defensa y protección de los espacios conquistados inter-

18 Ibid., p. 8. pretando, paralelamente a los civiles, los estratégicos creados por aquéllos para las fundaciones terrenas que reforzarian o se constituirian en otros centros regionales de inspiración misionera.

Mas en términos de instituciones coadyuvantes, desde las disposiciones imperiales hasta las ejecuciones de los colonos, pasando por las contradicciones que en buen número se presentaron entre el poder legal del Estado y el poder real de los colonos -aun potencialmente- otras instituciones resultan significativas para apreciar, desde un principio, la carga genética de las actuales regiones en la nación y el proceso de sus ciclos de vida e intermitencias.

Recurrimos nuevamente a José Miranda para rastrear una regionalización original que, aparentemente, parte del Estado (ultramarino, colonial y extranacional), pero que, en realidad, supone una dialéctica en la que la antítesis la constituye, en su momento, lo público y lo privado:

descle España o desde América, salían a rcalizar la conquista grupos de españoles, delegados de quien se arrogaba la soberanía, que constituían el embión de una provincia o región ultramarina de la monarquía hispánica. Estos grupos son en realidad las células primarias de las nuevas organizaciones políticas. Cabe decir que cada uno de ellos, como el de emigrantes del Mayflower, era una entidad política que iba en pos de un territorio para completarse. ${ }^{19}$

Hasta aquí Miranda nos propor-

19 Ibid., p. 30. 
ciona, a través de su análisis histórico, elementos muy válidos para apreciar la interacción que se estableció entre el Estado imperial y los colonos en relación con la formación de una región, a nivel macro y micro. De esa interacción surgirán las situaciones que, en el nivel de colonos mercedados y prebendados, se darán para establecer las condiciones del surgimiento de la nación y el establecimiento de un Estado emancipado de la tutela metropolitana.

Las concesiones reales a los particulares, a cambio del reconocimiento de éstos de la autoridad y de la soberanía imperial metropolitana, fue la base de un pacto que inició, descentralizadamente, entre 1521 y 1530 , la formación del espacio amplio y regional novohispano. Las capitulaciones constituyeron las reglas especiales, por medio de las cuales, los monarcas concertaron con los particulares determinadas estipulaciones, tratando de establecer y normar gubernamentalmente su presencia "continua y cercana" en la empresa, realmente inédita en la aún breve historia del reino español en América.

Los jefes de las expediciones o adelantados, capitanes generales, beneficiarios de cartas pueblas y fueros municipales tuvieron diversos privilegios: la participación principal en las ventajas económicas derivadas de la empresa mixta, la dirección de los participantes en ella (la hueste); como Miranda enumera:

el nombramiento de oficiales y magistrados; la superioridad en la justicia; la división territorial de su provincia o distrito; la confirmación de los alcaldes ordinarios; el establecimiento de ordenanzas para el gobierno de la tierra y para la labor de las minas. $-Y$ añadeal adelantado solían concedérscle, por merced especial, privilegios señoriales: vasallos, título nobiliario y el derecho de fundar mayorazgos. ${ }^{20}$

Tal concertación implicó, por el lado del concesionario, la obligación de funclar ciudades dentro de un tiempo convenido. A cambio recibiría la facultad de repartir tierras y solares, repartos que deberían ser ratificados por las autoridades superiores.

La necesidad de hacer expeditos los contactos políticos y comerciales con la metrópoli alentó la colonización de las costas. El resguardo del núcleo central del territorio colonial obligó al poblamiento de las fronteras de tierra adentro, desde las que partirian nuevos expedicionarios que ampliarian el territorio ocupado y adendarían nuevos y diversos recursos que explotar, comercializar internamente y transferir como capital a la metrópoli ultramarina.

La explotación de metales preciosos, azogue, sal, mano de obra africana e industrias manufactureras y extractivas diversas dieron origen a una consolidación de las redes comerciales y a nuevas formas, ya no tan estatales, de regionalización en las que los particulares ganaron terreno; sobre todo, los comerciantes y con ellos, sus concesionarios: los corregidores y alcaldes mayores. Entre 1531 y 1630, la búsqueda de un mayor control por parte del Estado revela el poder al que habían llevado sus licencias a los parti-

${ }^{20}$ Ibid., p. 33. 
culares. No obstante los contratos que la corona establecía con los particulares para darles mano libre en los monopolios comerciales de exportación e importación se mantenía dentro del carácter mixto original, los avances en el control territorial real fueron cayendo en manos de particulares, contestatarios frecuentes de las disposiciones del Estado colonial.

El control de centros de producción alimentaria y extracción minera, de redes comerciales, de estructuras políticas territoriales y de conductos funcionales que hicieron viables los poderes regionales frente a los poderes centrales virreinales $y$ peninsulares acentuaría consolidaciones regionales, como las de los bajíos occidentales, productores cerealeros y ganaderos; las zonas mineras guanajuatenses, zacatecanas y morelenses, entre otras, junto con sus productos sociales: oligarquias, obreros, comerciantes, burocrátas, clerecía, vagos y demás.

Sabemos poco sobre el conocimiento que el Estado borbón tuvo sobre la evolución y el poder regional en sus colonias. Sus reformas, sin embargo, indican la necesidad de intervenir en contra de una evidente autonomización general, de una nación en formación que, finalmente, lo consideraría adverso a sus intereses: Nucva España y sus regiones, a pesar de todo, ya constituían, potencialmente, una comunidad histórica, con una cultura $y$ un territorio comunes y una conciencia de pertenecer a ella que la Constitución de Cádiz, el campanazo de Dolores y la criolliza iturbidista harían emerger para bien o para mal.

No parece erróneo suponer que las especializaciones regionales en la pro- ducción y sus articulaciones en el conjunto tributario de la metrópoli fueron afectadas por las reformas borbónicas. Éstas fueron de significación diversa en una Nueva España con un territorio heterogéneo, continente de un muy desigual sistema de regiones con una historicidad y un desarrollo muy diverso.

Esto nos lleva a otro supuesto: a partir de la desarticulación interregional que Nueva España padeció a partir del movimiento emancipativo de 1810, el Estado liberal consolidado -ese interesante momento que los his. toriadores han bautizado como "la república restaurada"- dio origen, a partir de una nueva legalidad, a otras posibilidades de regionalización. Las leyes de desamortización no sólo intensificaron la circulación de las tierras como mercancía, sino que originaron un sensible movimiento de población. Regiones antes muy poco pobladas re. cibieron inmigrantes y cultivos, establecieron diversas industrias y crearon nuevos mercados. Las regiones llegaron a tener una gran autonomía y se fortalecieron con los capitales generados en su interior.

Fue la acción del Estado porfiriano que llegó a vincular numerosas re. giones con centros urbanos dominantes por medio del ferrocarril, el aumento de las importaciones y la especialización en cultivos de importación lo que comenzó a desdibujar los límites de numerosos espacios regionales. Los años de revolución que en múltiples regiones perduraron hasta los años treinta, la emigración, la cliversificación e intensificación de los medios de comunicación, la inclustrialización y modernización nacional y el 
férreo control de un partido-gobierno que ha favorecido el aprovechamiento de recursos regionales y la inversión de capitales extrarregionales han sido lo que finalmente acabó con regiones, autonomías, culturas locales e identidades. No obstante, grandes áreas, continentes de antiguas regiones, continúan considerándose como regiones. Tales son los casos del suroeste, el norte, el Golfo, el centro y el occidente de México, que tienen su espacio funcional y convencional y también tienen su historia particular.

\section{BIBLIOGRAFÍ}

-Bloch, Marc, French rural bistory: An essay on its basic characteristics, University of California Press, Berkeley y Los Ángeles, 1973.

-De bistoria e bistoriadores. "Home. naje a José Luis Romero", Siglo XXI Editores, México, 1982.

-De la Peña, Guillermo, "Los estudios regionales y la antropología social en
México", Relaciones, vol. II, núm. 8 , otoño de 1981.

-González y González, Luis, "De la múltiple utilización de la historia", en Carlos Pereyra y otros, Historia ipara que?, Siglo XXI Editores, México, 1980.

, La ronda de las generaciones, SEP-Cultura, México, 1983. El oficio de bistoriar, El

Colegio de Michoacán, México, 1988.

-Lewis, I. M. y otros, Historia y antropología, Seix Barral, Barcelona, 1972.

- Matute, Álvaro (comp.), La teoría de la bistorta en México: 19-40-1973, Secretaría de Educación Pública, México, 1974.

-Miranda, José, Las ideas y las instituciones politicas mexicanas, Instituto de Derecho Comparado-UnaM, México, 1952.

-Nisbet, Robert A., Social change and bistony, Oxford University Press, Oxford, 1969.

-O'Gorman, Edmundo, "Historia y vida", en Álvaro Matute (comp.), La teoría de la bistoria en México: 1940-1973, Secretatía de Educación Pública, México, 1974 (Sepsetentas).

-Vilar, Pierre, "Sobre los fundamentos de las estructuras nacionales", Historia 16, Maditid, Extra V (5-16), 1978. 